\title{
Targeting interleukin-6 for noninfectious uveitis
}

\author{
Phoebe Lin \\ Casey Eye Institute, Oregon Health \\ and Science University, Portland, OR, \\ USA
}

This article was published in the following Dove Press journal:

Clinical Ophthalmology

II September 2015

Number of times this article has been viewed
Abstract: Interleukin-6 (IL-6) is a pleiotropic cytokine implicated in the pathogenesis of many immune-mediated disorders including several types of non-infectious uveitis. These uveitic conditions include Vogt-Koyanagi-Harada syndrome, uveitis associated with Behçet disease, and sarcoidosis. This review summarizes the role of IL-6 in immunity, highlighting its effect on Th17, Th1, and plasmablast differentiation. It reviews the downstream mediators activated in the process of IL-6 binding to its receptor complex. This review also summarizes the biologics targeting either IL-6 or the IL-6 receptor, including tocilizumab, sarilumab, sirukumab, olokizumab, clazakizumab, and siltuximab. The target, dosage, potential side effects, and potential uses of these biologics are summarized in this article based on the existing literature. In summary, anti-IL-6 therapy for non-infectious uveitis shows promise in terms of efficacy and side effect profile.

Keywords: interleukin-6, T lymphocyte, B lymphocyte, autoimmunity, uveitis

\section{Role of interleukin-6 in immunity}

Interleukin-6 (IL-6) is a pleiotropic cytokine produced by monocytes, macrophages, T-lymphocytes, and synovial fibroblasts, as well as other cell types. It is produced in response to damage-associated molecular patterns in injury, and pathogen-associated molecular patterns via toll-like receptor signaling in autoimmunity and infection (Figure 1). IL-6 has a wide variety of effects on different cell types throughout the body, including induction of acute-phase reactant production by hepatocytes, B-lymphocyte differentiation, and T-lymphocyte subset differentiation (Figure 1). Specifically, IL-6 plays a critical role in differentiation of CD4-positive T helper (Th) cells into Th17 cells which have been strongly implicated in the pathogenesis of immune-mediated diseases including noninfectious uveitis. ${ }^{1,2}$ IL-6 can also induce differentiation of CD8-positive cells into cytotoxic T-cells.,3 IL-6 inhibits transforming growth factor $\beta$-mediated regulatory T-cell development, which is important in downregulating inflammatory responses. ${ }^{2,4}$ Additionally, IL-6 may be important in the pathogenesis of certain types of cancers, such as multiple myeloma. ${ }^{5}$

IL-6 signals in an autocrine and paracrine fashion by binding to the transmembrane cell surface IL-6 receptor as well as soluble IL- 6 receptor. ${ }^{2,6}$ The IL- 6 receptor includes the IL-6 binding domain (known as the IL-6 receptor) and the signal transduction chain, or gp130 (Figure 1A). ${ }^{7}$ Gp130 is common to other IL-6 family cytokines including interleukin-27 (IL-27), interleukin-35 (IL-35), interleukin-11 (IL-11), leukemia inhibitory factor (LIF), oncostatin M (OSM), ciliary neurotrophic factor (CNTF), cardiotrophin 1 (CTF1), and cardiotrophin-like cytokine (CLC). ${ }^{8}$

Activation of the IL-6 receptor requires a hexameric structure consisting of two molecules each of the IL-6 receptor, IL-6, and gp130.7 Activated gp130 results in activation of Janus kinase (JAK) and signal transducer and activator of transcription 3 (STAT3) pathways. ${ }^{2,6,8,9} \mathrm{SH} 2$-domain containing tyrosine phosphatase-2 and mitogen activated protein kinases (MAPK) are also activated. ${ }^{8}$ IL-6 responsive genes include 
A

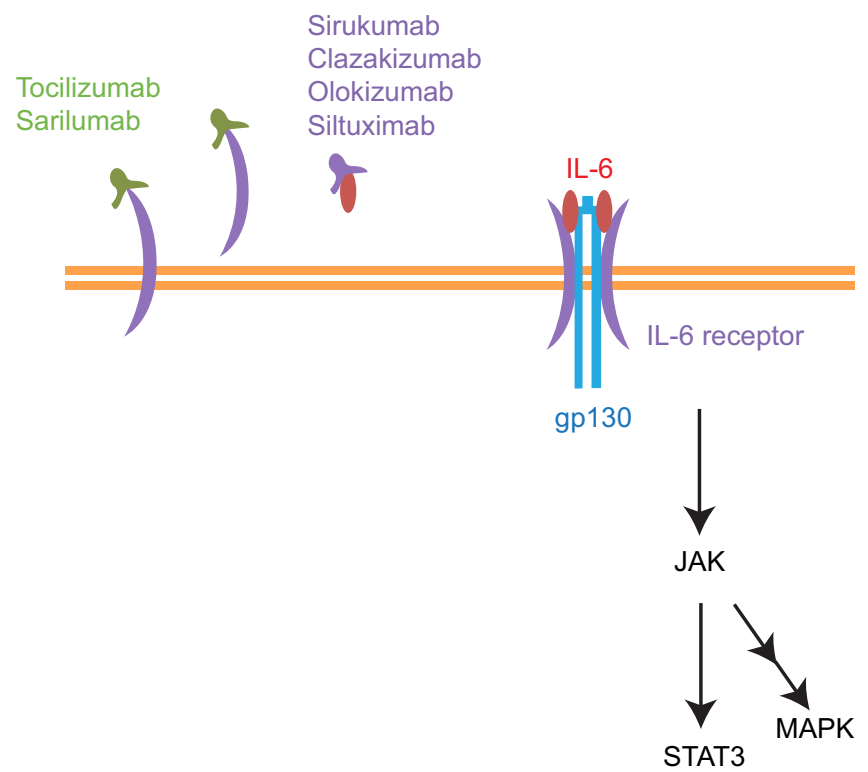

B

Effects on the immune system

+ Th0 $\rightarrow$ Th17

$+\mathrm{Th} 0 \rightarrow$ Th1

+ CD8+ T-cell $\rightarrow$ cytotoxic T lymphocyte

$+\mathrm{B}$ cell $\rightarrow$ plasmablast

+ Angiogenesis and vascular permeability

- Th0 $\rightarrow$ Treg

Effects on the bones and bone marrow Increases osteoclast differentiation Increases platelets Increases multipotent colony formation

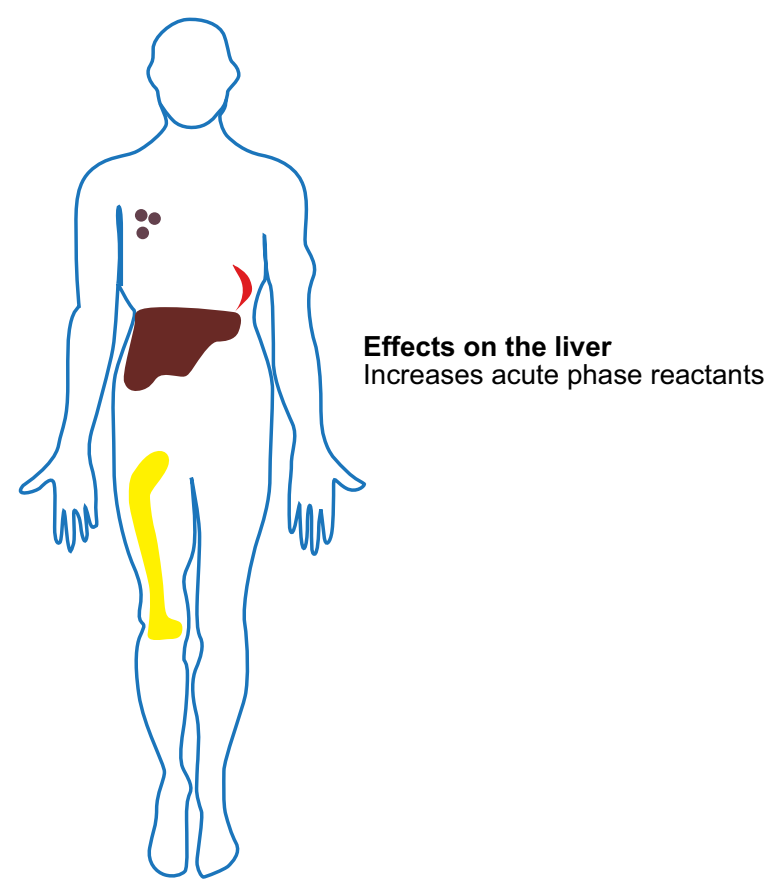

Figure I Signaling and activity of IL-6.

Notes: (A) Signaling of IL-6 occurs through its receptor and gp I 30 in a heterotrimeric complex. The targets of IL- 6 biologics are also shown. (B) Biological activity of IL-6 in various human organ systems. Modified with permission of Elsevier from: A new era for the treatment of inflammatory autoimmune diseases by interleukin-6 blockade strategy, Tanaka et al; Semin Immunol. (C) 20I4; 26(I). ${ }^{8}$ Permission conveyed through Copyright Clearance Centre, Inc.

Abbreviations: JAK, janus kinase; STAT3, signal transducer and activator of transcription 3; MAPK, mitogen activated protein kinase.

the acute phase reactants $\mathrm{C}$-reactive protein, fibrinogen, and serum amyloid A. ${ }^{10}$ They also include hepcidin which blocks the action of ferroportin, an iron transporter in the gut, thus contributing to anemia of chronic inflammatory disease. ${ }^{11}$ Importantly, IL-6 can induce production of vascular endothelial growth factor, resulting in the neovascular process that can sometimes accompany inflammation. ${ }^{12}$

The production of IL- 6 is regulated by certain microRNAs such as miRNA-155, and proteins such as Regnase-1, which negatively regulates IL-6 production by cells. Another regulator of IL-6 is the protein Arid5a (AT-rich interactive domain-containing protein 5a), which stabilizes IL-6 mRNA. ${ }^{13}$

\section{Role of IL-6 in uveitis and other immune-mediated diseases}

Both preclinical and clinical data support the importance of IL-6 in uveitis. Yoshimura et a ${ }^{14}$ demonstrated the 
importance of IL-6 in an animal model of T-cell mediated uveitis, experimental autoimmune uveitis (EAU), by showing that treatment of EAU mice with an anti-IL-6 receptor antibody or, alternatively, EAU induction in IL-6-deficient mice results in dramatically reduced uveitic inflammation. This effect in EAU appears to occur via the suppression of both Th1 and Th17 differentiation, both of which are important in this animal model of uveitis. ${ }^{15}$ These same authors demonstrated elevated IL-6 concentrations in the vitreous fluid of chronic uveitis patients (with Vogt-Koyanagi-Harada syndrome, Behçet disease, sarcoidosis, and idiopathic uveitis), compared to nonuveitic patients (samples obtained from diabetic retinopathy, epiretinal membrane, and macular hole patients). ${ }^{14}$ Perez et al ${ }^{16}$ demonstrated that IL- 6 was higher in the vitreous of patients with active intermediate or posterior uveitis compared to control patients. Even prior to the two above publications, however, Murray et $\mathrm{al}^{17}$ had demonstrated elevated aqueous humor levels of IL-6 in 24 patients with uveitis including in Fuchs' heterochromic iridocyclitis $(n=16)$ and Toxoplasma uveitis $(n=8)$. IL-6 levels are elevated in the serum of active uveitis patients as well. ${ }^{18}$

While rheumatoid arthritis (RA) is not commonly associated with uveitis, IL- 6 production is dysregulated in the synovial fluid of RA patients. ${ }^{19}$ IL-6 and soluble IL-6 receptor are elevated in the serum of RA patients, and appear to correlate with disease activity. ${ }^{20}$ Castleman disease, a condition resulting in lymphadenopathy, fever, night sweats, fatigue, and weight loss, is very rarely associated with uveitis. ${ }^{21}$ Oshitari et $\mathrm{a}^{21}$ showed that IL-6 aqueous levels were elevated in a patient with Castleman disease with anterior uveitis and retinal vasculitis resistant to oral steroid treatment but amenable to anti-IL-6 receptor antibody treatment. In juvenile idiopathic arthritis (JIA), serum IL-6 appears to be elevated in patients with active disease compared to inactive disease. It has been demonstrated that IL-6 levels decrease upon treatment in these patients. ${ }^{22,23}$ Table 1 summarizes the uveitic and systemic disorders associated with dysregulated IL-6 or IL-6 receptor (Table 1).

\section{Targeting IL-6 for uveitis and systemic inflammatory disorders}

Tocilizumab (Genentech, South San Francisco, CA, USA) is a monoclonal antibody against soluble and membrane-bound IL-6 receptor that is approved for the treatment of moderate to severe RA and JIA that has failed treatment with other disease modifying biologics. It has been used successfully in case reports in JIA uveitis refractory to prior TNF- $\alpha$ blockade, ${ }^{24,25}$ Castleman disease-associated uveitis, birdshot
Table I Conditions in which IL-6 plays a role in pathogenesis

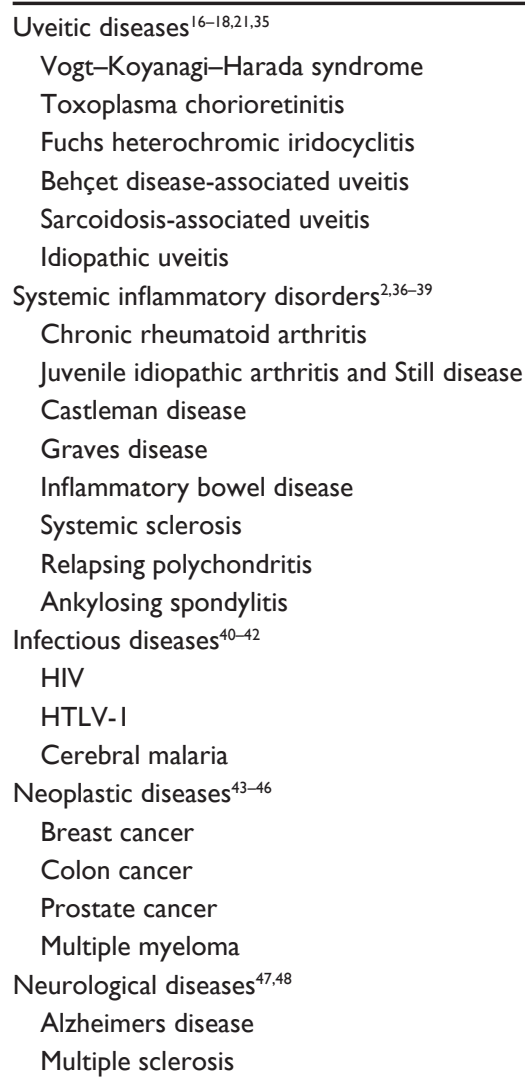

Note: Modified from Interleukin-6 blockade in ocular inflammatory diseases. Mesquida M, et al; Clin Exp Immunol. 2014;176(3)..$^{15}$ ๑ 2014 John Wiley and Sons Inc. Abbreviation: HTLV-I, human T-lymphotropic virus-I.

chorioretinopathy, Behçet disease, and refractory idiopathic uveitis. ${ }^{15,26-28}$ Doses used are described in Table 2.

In a retrospective study of eight eyes from five patients with uveitic cystoid macular edema (CME) refractory to traditional immunosuppressive therapy or anti-TNF- $\alpha$ treatment, Adan et $\mathrm{al}^{26}$ showed that tocilizumab was effective in treating CME at month 1 , and as late as 6 months after follow-up. Tocilizumab maintained control of macular edema even after tapering other immunosuppressive agents. ${ }^{26}$ The same group also published a series involving eleven eyes from seven patients with uveitic CME due to birdshot chorioretinopathy, JIA, and idiopathic panuveitis. ${ }^{27}$ Both mean $\operatorname{logMAR}$ visual acuity and central foveal thickness by optical coherence tomography (OCT) improved after treatment with tocilizumab at the 1 year follow-up. Two patients withdrew from the study due to sustained remission at 12 months, but in both patients, CME relapsed within 3 months after tocilizumab withdrawal. No serious adverse events were reported in this small study of uveitis patients. ${ }^{27}$ In a separate study, Papo et $\mathrm{a}^{28}$ treated eight consecutive severe refractory uveitis patients with $8 \mathrm{mg} / \mathrm{kg}$ of tocilizumab, IV, every 4 weeks. They showed that six out of the eight patients 
Table 2 Summary of anti-IL-6 or IL-6R biologics

\begin{tabular}{|c|c|c|c|c|}
\hline Biologic name & Molecular target & Company & Studied dosing & Potential uses \\
\hline Tocilizumab $^{13,15,24,26,27}$ & $\begin{array}{l}\text { Membrane and } \\
\text { soluble IL-6 receptor }\end{array}$ & Genentech & $\begin{array}{l}4 \text { or } 8 \mathrm{mg} / \mathrm{kg} \text { IV q4wk for } \\
6 \text { doses or } 162 \mathrm{mg} \mathrm{SC} \text { qwk }\end{array}$ & $\begin{array}{l}\text { RA, JIA, Castleman disease, } \\
\text { Behçet disease, systemic sclerosis, } \\
\text { uveitis }\end{array}$ \\
\hline Sarilumab ${ }^{31}$ & $\begin{array}{l}\text { Membrane and } \\
\text { soluble IL-6 receptor }\end{array}$ & Regeneron & I50-200 mg SC q2wk & RA, uveitis \\
\hline Sirukumab ${ }^{30}$ & IL-6 & Janssen & $100 \mathrm{mg} \mathrm{SC}$ q2wk & RA \\
\hline Olokizumab 32 & IL-6 & UCB & $60-240 \mathrm{mg}$ SC q2-4wk & RA \\
\hline Clazakizumab ${ }^{33}$ & IL-6 & $\begin{array}{l}\text { Alder } \\
\text { BioPharmaceuticals }\end{array}$ & $\begin{array}{l}80-320 \mathrm{mg} \text { IV on day I, and } \\
\text { week } 8\end{array}$ & RA \\
\hline Siltuximab ${ }^{34}$ & IL-6 & Janssen & II mg/kg IV q3wk & $\begin{array}{l}\text { Castleman disease, multiple myeloma, } \\
\text { prostate cancer }\end{array}$ \\
\hline
\end{tabular}

Note: Bold denotes FDA-approved uses.

Abbreviations: IV, intravenous; RA, rheumatoid arthritis; JIA, juvenile idiopathic arthritis; SC, subcutaneous; q4wk, every 4 weeks; q2-4wk, every 2 to 4 weeks; q3wk, every 3 weeks.

responded to tocilizumab with visual acuity improvement in five patients. Side effects included bronchitis $(n=1)$, leukopenia $(n=1)$, and thrombocytopenia $(n=1)$. Two separate Phase I/II clinical trials are ongoing (www.clinicaltrials.gov) to study the efficacy of tocilizumab in noninfectious intermediate, posterior or panuveitis (STOP-Uveitis) and in JIA-associated uveitis. ${ }^{13} \mathrm{~A}$ Phase III clinical trial for tocilizumab (also at www.clinicaltrials.gov) in the treatment of sight-threatening Graves orbitopathy not responsive to intravenous corticosteroids is also enrolling patients.

Sirukumab (Janssen Biologics, Horsham, PA Glaxo SmithKline, Brentford, UK), a human monoclonal antibody that binds IL-6, is currently undergoing a Phase III clinical trial for RA not responsive to methotrexate or anti-TNF- $\alpha$ treatment, and is being studied as monotherapy in a comparative efficacy trial with adalimumab. ${ }^{29}$ Smolen et al ${ }^{30}$ reported the results of a Phase II study in RA patients refractory to methotrexate. In their study, the primary endpoint of ACR50 scores was achieved at week 12 using sirukumab $100 \mathrm{mg}$ every 2 weeks. ACR50 refers to a $50 \%$ improvement in RA as determined by guidelines set forth by the American College of Rheumatology. This is determined by the percentage of improvement in tender and swollen joints.

Sarilumab (Regeneron Pharmaceuticals, Tarrytown, NY, USA) is a human anti-IL-6 receptor monoclonal antibody also undergoing several Phase III clinical trials for use as monotherapy and in conjunction with drugs like methtorexate therapy for RA. In a study in which 306 active RA patients refractory to methotrexate treatment were randomized to 1 of 6 treatment arms of varying doses of sarilumab, the proportion of patients achieving the primary endpoint, based on an ACR20 (20\% improvement according to guidelines set forth by the American College of Rheumatology) at week 12, was higher in sarilumab $150 \mathrm{mg}$ weekly or every other week groups compared with the placebo. ${ }^{31}$ A multicenter Phase II trial, the SATURN Study, to evaluate the efficacy of sarilumab in noninfectious intermediate, posterior, and panuveitis is currently enrolling subjects. ${ }^{13}$

Other IL-6 biologics include olokizumab (UCB, Brussels, Belgium), clazakizumab (Alder BioPharmaceuticals, Bothell, WA, USA), and siltuximab (Janssen, Horsham, PA, USA). Olokizumab is a humanized anti-IL-6 monoclonal antibody that was effective in a 12 week Phase IIb study in RA patients who were refractory to TNF inhibitors. ${ }^{32}$ Clazakizumab is also a humanized anti-IL-6 monoclonal antibody that achieved its primary endpoint in treating RA patients refractory to methotrexate. ${ }^{33}$ Siltuximab (CNTO 328) is a human-murine anti-IL-6 monoclonal antibody, which has been studied in clinical trials for a number of diseases including prostate cancer, renal cancer, ovarian cancer, Castleman disease, and multiple myeloma. ${ }^{6,34}$ Table 2 summarizes the biologics targeting IL-6 or the IL-6 receptor.

\section{Adverse side effects and work up}

Commonly reported adverse events that have been reported in the clinical trials for anti-IL-6 or IL-6 receptor antibodies appear to be similar, and include gastrointestinal disorders, respiratory tract infections, urinary tract infections, and nervous system disorders. ${ }^{29}$ No cases of tuberculosis were reported, although most patients will have received testing to rule out tuberculosis prior to receiving these therapies. Common laboratory findings included neutropenia or other hematologic changes, elevated liver function tests, and elevated serum lipids, although establishing a causal role for these changes with these biologics requires further investigation. ${ }^{29-31,33}$

\section{Disclosure}

The author reports no conflicts of interest in this work. 


\section{References}

1. Korn T, Mitsdoerffer M, Croxford AL, et al. IL-6 controls Th17 immunity in vivo by inhibiting the conversion of conventional $\mathrm{T}$ cells into Foxp3+ regulatory T cells. Proc Natl Acad Sci U S A. 2008;105(47):18460-18465.

2. Tanaka T, Narazaki M, Kishimoto T. IL-6 in inflammation, immunity, and disease. Cold Spring Harb Perspect Biol. 2014;6(10): a016295.

3. Okada M, Kitahara M, Kishimoto S, Matsuda T, Hirano T, Kishimoto T. IL-6/BSF-2 functions as a killer helper factor in the in vitro induction of cytotoxic T cells. J Immunol. 1988;141(5):1543-1549.

4. Bettelli E, Carrier Y, Gao W, et al. Reciprocal developmental pathways for the generation of pathogenic effector TH17 and regulatory T cells. Nature. 2006;441(7090):235-238.

5. Voorhees PM, Chen Q, Small GW, et al. Targeted inhibition of interleukin-6 with CNTO 328 sensitizes pre-clinical models of multiple myeloma to dexamethasone-mediated cell death. Br J Haematol. 2009;145(4):481-490.

6. Ataie-Kachoie P, Pourgholami MH, Morris DL. Inhibition of the IL-6 signaling pathway: a strategy to combat chronic inflammatory diseases and cancer. Cytokine Growth Factor Rev. 2013;24(2): 163-173.

7. Yamasaki K, Taga T, Hirata Y, et al. Cloning and expression of the human interleukin-6 (BSF-2/IFN beta 2) receptor. Science. 1988;241(4867):825-828.

8. Tanaka T, Narazaki M, Ogata A, Kishimoto T. A new era for the treatment of inflammatory autoimmune diseases by interleukin- 6 blockade strategy. Semin Immunol. 2014;26(1):88-96.

9. Kim NH, Lee MY, Park SJ, Choi JS, Oh MK, Kim IS. Auranofin blocks interleukin-6 signalling by inhibiting phosphorylation of JAK1 and STAT3. Immunology. 2007;122(4):607-614.

10. Heinrich PC, Castell JV, Andus T. Interleukin-6 and the acute phase response. Biochem J. 1990;265(3):621-636.

11. Nemeth E, Rivera S, Gabayan V, et al. IL-6 mediates hypoferremia of inflammation by inducing the synthesis of the iron regulatory hormone hepcidin. J Clin Invest. 2004;113(9):1271-1276.

12. Tzeng HE, Tsai CH, Chang ZL, et al. Interleukin-6 induces vascular endothelial growth factor expression and promotes angiogenesis through apoptosis signal-regulating kinase 1 in human osteosarcoma. Biochem Pharmacol. 2013;85(4):531-540.

13. Maya JR, Sadiq MA, Zapata LJ, et al. Emerging therapies for noninfectious uveitis: what may be coming to the clinics. J Ophthalmol. 2014;2014:310329.

14. Yoshimura T, Sonoda KH, Ohguro N, et al. Involvement of Th17 cells and the effect of anti-IL-6 therapy in autoimmune uveitis. Rheumatology. 2009;48(4):347-354.

15. Mesquida M, Leszczynska A, Llorenc V, Adan A. Interleukin-6 blockade in ocular inflammatory diseases. Clin Exp Immunol. 2014;176(3): 301-309.

16. Perez VL, Papaliodis GN, Chu D, Anzaar F, Christen W, Foster CS. Elevated levels of interleukin 6 in the vitreous fluid of patients with pars planitis and posterior uveitis: the Massachusetts eye and ear experience and review of previous studies. Ocul Immunol Inflamm. 2004;12(3): 193-201.

17. Murray PI, Hoekzema R, van Haren MA, de Hon FD, Kijlstra A. Aqueous humor interleukin-6 levels in uveitis. Invest Ophthalmol Vis Sci. 1990;31(5):917-920.

18. Kramer M, Monselise Y, Bahar I, Cohen Y, Weinberger D, GoldenbergCohen N. Serum cytokine levels in active uveitis and remission. Curr Eye Res. 2007;32(7-8):669-675.

19. Hirano T, Matsuda T, Turner M, et al. Excessive production of interleukin 6/B cell stimulatory factor-2 in rheumatoid arthritis. Eur J Immunol. 1988;18(11):1797-1801.

20. Stuart RA, Littlewood AJ, Maddison PJ, Hall ND. Elevated serum interleukin-6 levels associated with active disease in systemic connective tissue disorders. Clin Exp Rheumatol. 1995;13(1):17-22.
21. Oshitari T, Kajita F, Tobe A, et al. Refractory uveitis in patient with castleman disease successfully treated with tocilizumab. Case Rep Ophthalmol Med. 2012;2012:968180.

22. Kaminiarczyk-Pyzalka D, Adamczak K, Mikos H, Klimecka I, Moczko J, Niedziela M. Proinflammatory cytokines in monitoring the course of disease and effectiveness of treatment with etanercept (ETN) of children with oligo- and polyarticular juvenile idiopathic arthritis (JIA). Clin Lab. 2014;60(9):1481-1490.

23. Spirchez M, Samasca G, Iancu M, Bolba C, Miu N. Relation of interleukin-6, TNF-alpha and interleukin-1alpha with disease activity and severity in juvenile idiopathic arthritis patients. Clin Lab. 2012;58(3-4):253-260.

24. Tappeiner C, Heinz C, Ganser G, Heiligenhaus A. Is tocilizumab an effective option for treatment of refractory uveitis associated with juvenile idiopathic arthritis? J Rheumatol. 2012;39(6):1294-1295.

25. Tsang AC, Roth J, Gottlieb C. Tocilizumab for severe chronic anterior uveitis associated with juvenile idiopathic arthritis in a pediatric patient. Ocul Immunol Inflamm. 2014;22(2):155-157.

26. Adan A, Mesquida M, Llorenc V, et al. Tocilizumab treatment for refractory uveitis-related cystoid macular edema. Graefes Arch Clin Exp Ophthalmol. 2013;251(11):2627-2632.

27. Mesquida M, Molins B, Llorenc V, Sainz de la Maza M, Adan A. Long-term effects of tocilizumab therapy for refractory uveitis-related macular edema. Ophthalmology. 2014;121(12):2380-2386.

28. Papo M, Bielefeld P, Vallet H, et al. Tocilizumab in severe and refractory non-infectious uveitis. Clin Exp Rheumatol. 2014;32(4 Supp1 84): S75-S79.

29. Tanaka Y, Martin Mola E. IL-6 targeting compared to TNF targeting in rheumatoid arthritis: studies of olokizumab, sarilumab and sirukumab. Ann Rheum Dis. 2014;73(9):1595-1597.

30. Smolen JS, Weinblatt ME, Sheng S, Zhuang Y, Hsu B. Sirukumab, a human anti-interleukin-6 monoclonal antibody: a randomised, 2-part (proof-of-concept and dose-finding), phase II study in patients with active rheumatoid arthritis despite methotrexate therapy. Ann Rheum Dis. 2014;73(9):1616-1625.

31. Huizinga TW, Fleischmann RM, Jasson M, et al. Sarilumab, a fully human monoclonal antibody against IL-6Ralpha in patients with rheumatoid arthritis and an inadequate response to methotrexate: efficacy and safety results from the randomised SARIL-RA-MOBILITY Part A trial. Ann Rheum Dis. 2014;73(9):1626-1634.

32. Genovese MC, Fleischmann R, Furst D, et al. Efficacy and safety of olokizumab in patients with rheumatoid arthritis with an inadequate response to TNF inhibitor therapy: outcomes of a randomised Phase IIb study. Ann Rheum Dis. 2014;73(9):1607-1615.

33. Mease P, Strand V, Shalamberidze L, et al. A phase II, double-blind, randomised, placebo-controlled study of BMS945429 (ALD518) in patients with rheumatoid arthritis with an inadequate response to methotrexate. Ann Rheum Dis. 2012;71(7):1183-1189.

34. Kurzrock R, Voorhees PM, Casper C, et al. A phase I, open-label study of siltuximab, an anti-IL-6 monoclonal antibody, in patients with B-cell non-Hodgkin lymphoma, multiple myeloma, or Castleman disease. Clin Cancer Res. 2013;19(13):3659-3670.

35. El-Asrar AM, Struyf S, Kangave D, et al. Cytokine profiles in aqueous humor of patients with different clinical entities of endogenous uveitis. Clin Immunol. 2011;139(2):177-184.

36. Montero-Julian FA. The soluble IL-6 receptors: serum levels and biological function. Cell Mol Biol. 2001;47(4):583-597.

37. Muangchant C, Pope JE. The significance of interleukin-6 and C-reactive protein in systemic sclerosis: a systematic literature review. Clin Exp Rheumatol. 2013;31(2 Suppl 76):122-134.

38. Pignatti P, Ciapponi L, Galle P, et al. High circulating levels of biologically inactive IL-6/SIL-6 receptor complexes in systemic juvenile idiopathic arthritis: evidence for serum factors interfering with the binding to gp130. Clin Exp Immunol. 2003;131(2):355-363.

39. Shimamoto K, Ito T, Ozaki Y, et al. Serum interleukin 6 before and after therapy with tocilizumab is a principal biomarker in patients with rheumatoid arthritis. J Rheumatol. 2013;40(7):1074-1081. 
40. Borges AH, O'Connor JL, Phillips AN, et al. Factors associated with plasma IL-6 levels during HIV infection. J Infect Dis. Epub February 26, 2015.

41. Lyke KE, Burges R, Cissoko Y, et al. Serum levels of the proinflammatory cytokines interleukin-1 beta (IL-1beta), IL-6, IL-8, IL-10, tumor necrosis factor alpha, and IL-12(p70) in Malian children with severe Plasmodium falciparum malaria and matched uncomplicated malaria or healthy controls. Infect Immun. 2004;72(10):5630-5637.

42. Zhou Y, Horiuchi S, Yamamoto M, Yamamoto N. Elevated serum levels of the soluble form of gp130, the IL-6 signal transducer, in HTLV-1 infection and no involvement of alternative splicing for its generation. Microbiol Immunol. 1998;42(2):109-116.

43. Chi N, Tan Z, Ma K, Bao L, Yun Z. Increased circulating myeloid-derived suppressor cells correlate with cancer stages, interleukin-8 and -6 in prostate cancer. Int J Clin Exp Med. 2014;7(10):3181-3192.

44. Lu CC, Kuo HC, Wang FS, Jou MH, Lee KC, Chuang JH. Upregulation of TLRs and IL-6 as a marker in human colorectal cancer. Int J Mol Sci. 2015;16(1):159-177.
45. Markkula A, Simonsson M, Ingvar C, Rose C, Jernstrom H. IL6 genotype, tumour ER-status, and treatment predicted disease-free survival in a prospective breast cancer cohort. BMC Cancer. 2014;14:759.

46. Neemat K, Rania K, Tarek M, Hamdy AA. Effect of 13q deletion on IL-6 production in patients with multiple myeloma: a hypothesis may hold true. Clin Lab. 2014;60(8):1393-1399.

47. Malmestrom C, Andersson BA, Haghighi S, Lycke J. IL-6 and CCL2 levels in CSF are associated with the clinical course of MS: implications for their possible immunopathogenic roles. J Neuroimmunol. 2006;175(1-2):176-182.

48. Uslu S, Akarkarasu ZE, Ozbabalik D, et al. Levels of amyloid beta-42, interleukin-6 and tumor necrosis factor-alpha in Alzheimer's disease and vascular dementia. Neurochem Res. 2012;37(7): 1554-1559.
Clinical Ophthalmology

\section{Publish your work in this journal}

Clinical Ophthalmology is an international, peer-reviewed journal covering all subspecialties within ophthalmology. Key topics include: Optometry; Visual science; Pharmacology and drug therapy in eye diseases; Basic Sciences; Primary and Secondary eye care; Patient Safety and Quality of Care Improvements. This journal is indexed on

\section{Dovepress}

PubMed Central and CAS, and is the official journal of The Society of Clinical Ophthalmology (SCO). The manuscript management system is completely online and includes a very quick and fair peer-review system, which is all easy to use. Visit http://www.dovepress.com/ testimonials.php to read real quotes from published authors. 